\title{
Reviews
}

\section{Molecular genetics of solid tumours: translating research into clinical practice. What we could do now: breast cancer}

\author{
S R Lakhani
}

\begin{abstract}
Breast cancer is a common solid malignancy in women. Over the past decade, much progress has been made in understanding the biology of breast cancer. The use of molecular and immunohistochemical techniques is providing insights that will allow us to tailor the management of patients with breast cancer. In this review, progress in the understanding of lobular carcinoma in situ and atypical ductal hyperplasia, the use of the molecular marker CerbB2, and information gained from the morphological analysis of tumours arising in patients with BRCA1 and BRCA2 mutations is discussed. (F Clin Pathol: Mol Pathol 2001;54:281-284)
\end{abstract}

Keywords: breast cancer; lobular carcinoma in situ; atypical ductal hyperplasia; CerbB2,; BRCA1 mutation; BRCA2 mutation; molecular markers

There is compelling evidence that breast cancers arise in a multistep fashion through a series of intermediate "hyperplastic" and neoplastic lesions, each of which has a greater chance of becoming malignant than the one that preceded it. ${ }^{1}$ The reliable recognition of these stages is of great value in learning more about the pathogenesis and possible aetiology of human breast cancer, and in identifying women who are at increased risk of developing the disease.

The introduction of mammographic screening has led to increased detection of premalignant lesions, in particular ductal carcinoma in situ (DCIS). ${ }^{2}$ The classification of intraductal proliferations is controversial and pathologists encounter difficulties in subclassifying DCIS, differentiating it from atypical ductal hyperplasia $(\mathrm{ADH})$, and distinguishing lobular carcinoma in situ (LCIS) from the solid variant of low nuclear grade DCIS. However, in situ carcinomas and atypical hyperplasias are not the only abnormalities thought to be precancerous, and some commonly encountered benign lesions also appear to be associated with increased cancer risk. There can be considerable difficulty in determining whether a particular lesion is premalignant and the degree of risk with which it is associated. Furthermore, it may not be possible to distinguish those that are genuine precursors from those that are merely associated with cancer and consequently markers or indicators of risk.

\section{Lobular carcinoma in situ (LCIS)}

LCIS was described in 1941 by Foote and Stewart, ${ }^{4}$ although it had been recognised as a precancerous lesion some years before. ${ }^{5}$ Most cases of LCIS are diagnosed between the ages of 40 and 50 years, a decade earlier than DCIS. LCIS is not generally palpable and there are usually no mammographic abnormalities. ${ }^{6}$ Hence, it is usually an incidental finding in biopsies done for an unrelated benign or malignant condition. It is often multifocal and bilateral. More that $50 \%$ of the patients with LCIS have further disease in the ipsilateral breast and approximately a third of patients will have LCIS in the contralateral breast. ${ }^{7-9}$ Although Page et al reported that approximately two thirds of women will develop invasive carcinoma within 15 years of follow up, ${ }^{10}$ other studies suggest a lower risk (20\%), and most cancers do not appear until 15-20 years later. ${ }^{11}{ }^{12}$ Interestingly, only half the invasive cancers are lobular in type, the rest being invasive ductal carcinoma. Unlike DCIS, the risk of invasive carcinoma after LCIS is bilateral. ${ }^{10}{ }^{13}$

These features have raised questions about the biological nature of LCIS. Although originally described as an "in situ carcinoma", with the implication that it was an invasive cancer in the making, the view has now changed to a "risk indicator". Since the original description by Foote and Stewart, ${ }^{4}$ the trend has swung from mastectomy to follow up, follow up with regular mammography, and even "no action". ${ }^{13-15}$

Although it is recognised that a proportion of women with LCIS will go on to develop invasive carcinoma, at present, there are no clinical or morphological features that allow identification of the women at risk. This has created a problem for surgeons and oncologists managing patients who have a diagnosis of carcinoma in situ but in whom the lesion has uncertain significance.

Although LCIS has been documented as an entity for nearly 50 years, molecular data are 
limited. E-cadherin, an epithelial cell-cell adhesion molecule, is often found in DCIS and invasive ductal carcinoma, but is rarely seen in LCIS or invasive lobular carcinoma. ${ }^{16}{ }^{17} \mathrm{La}-$ khani et al reported that loss of heterozygosity $(\mathrm{LOH})$ involving chromosomal loci at high frequency in invasive carcinoma can also be detected in LCIS. ${ }^{18}$ The frequency in their study ranged from $8 \%$ on chromosome $17 \mathrm{p}$ to $50 \%$ on $17 \mathrm{q}$. LOH on chromosome $16 \mathrm{q}$, the site of the E-cadherin gene was approximately $30 \%$. LOH was identified in LCIS with and without invasive carcinoma. This confirmed the neoplastic nature of LCIS and suggested that LCIS was probably a direct precursor of invasive cancer. Further support for this hypothesis has come from Nayar et al, ${ }^{19}$ who showed LOH in $50 \%$ of LCIS associated with invasive carcinoma at markers on chromosome $11 \mathrm{q} 13$.

The most direct evidence for a precursor role of LCIS comes from mutational analysis of the E-cadherin gene. Berx et al found that 27 of 48 invasive lobular carcinomas had mutations in the E-cadherin gene, whereas none of 50 breast cancers of other types had alterations. ${ }^{20}{ }^{21}$ The same group subsequently demonstrated that truncating mutations identified in invasive lobular carcinoma were also present in the adjacent LCIS, providing strong evidence that LCIS is a precursor lesion. ${ }^{22}$

There can be little doubt now that LCIS is a precursor of invasive cancer. Unfortunately, the data still do not allow us to stratify patients into meaningful groups for management. We still have no way of identifying the one in five women who need regular follow up or treatment for LCIS. The hope is that newer technologies, such as transcription profiling, ${ }^{23}$ will help us to achieve that aim.

\section{Atypical ductal hyperplasia (ADH)}

$\mathrm{ADH}$ is a proliferation that exhibits some but not all the morphological features of DCIS and hence, by definition, shares histological features with carcinoma. Follow up studies have confirmed the precancerous nature of $\mathrm{ADH}$. Page and his colleagues conducted a series of important prospective studies in the 1980s. In one of these ${ }^{24}$ they indicated that the relative risk of developing carcinoma in a woman with proliferative disease was 1.9 and this rose to 5.3 if the proliferation showed evidence of atypia. This risk was doubled in the presence of a positive family history of breast cancer. Subsequently, Tavassoli and Norris, ${ }^{25} \mathrm{McDivitt}$ et $a l^{26}$ and London and colleagues ${ }^{27}$ have confirmed the increased risk associated with atypical hyperplasia, although the size of the risk has varied between studies.

However, $\mathrm{ADH}$ is a controversial entity, which poses considerable difficulties in diagnostic pathology. To solve this problem, Page and Rogers ${ }^{28}$ laid down clear guidelines for diagnosis and a subsequent study by Schnitt et $a l,{ }^{29}$ in which the Page and Rogers criteria were used, showed an improvement, with complete agreement in $58 \%$ of cases. Other studies, including those associated with the UK National and European Commission Quality
Assurance Schemes (EQA), have revealed lower levels of agreement even among experienced breast pathologists. ${ }^{30-32}$

Lakhani et al demonstrated that $\mathrm{LOH}$ identified at loci on $16 \mathrm{q}$ and $17 \mathrm{p}$ in in situ and invasive cancer is also present in $\mathrm{ADH}$ with a similar frequency. ${ }^{33}$ This indicates that $\mathrm{ADH}$ is a neoplastic proliferation and is likely to be part of the spectrum of in situ ductal neoplasia. There is support for this view in the literature from several other studies. ${ }^{34-36} \mathrm{O}^{\prime}$ Connell et al studied 51 cases of ADH at 15 polymorphic microsatellite loci and found $\mathrm{LOH}$ for at least one marker in $42 \%$ of the cases. ${ }^{36}$ The studies suggest that there is little difference between $\mathrm{ADH}$ and DCIS within the limits of current molecular investigations. The failure of EQA schemes to demonstrate reasonable agreement for this category, together with molecular data, which show pronounced overlap between $\mathrm{ADH}$, and DCIS raise serious doubts about the validity of this diagnostic category. If future experiments do show that $\mathrm{ADH}$ is distinct from DCIS, more robust diagnostic criteria will have to be developed for use in clinical practice.

\section{CerbB2 oncogene and Herceptin}

The protooncogene CerbB2 (Her2/Neu) encodes a transmembrane protein, which has homology with epidermal growth factor receptor. CerbB2 is amplified in approximately $20 \%$ of invasive cancers and has received interest because of its association with lymph node metastases, short relapse time, poor survival, and decreased response to endocrine and chemotherapy. ${ }^{37-39}$ CerbB2 amplification is almost always associated with an increase in mRNA and protein expression. In contrast to invasive cancer, the CerbB2 protein has been identified in a high proportion $(60-80 \%)$ of DCIS of high nuclear grade, comedo-type, but is not common in the low nuclear grade forms. Allred et al found that the expression of this protein is higher in invasive carcinomas associated with DCIS than in those without DCIS. ${ }^{40}$ It is very rarely expressed in LCIS. ${ }^{41-43}$ This gene product has not been identified in benign proliferative disease or ADH. ${ }^{44}$ This oncogene represents an excellent example of the translation of basic science to clinical practice. CerbB2 status predicts response to antioestrogen and cytotoxic chemotherapy. CerbB2 has attracted attention because of the availability of the humanised monoclonal antibody Herceptin for the treatment of breast cancer. Initial clinical trails suggest that it will have a useful role in the management of a proportion of breast cancers. ${ }^{45}$

\section{Familial breast cancer}

A small proportion of breast cancers result from a heritable predisposition. Two predisposition genes, BRCA1 and BRCA 2 have been cloned. The morphological features of tumours from patients with BRCA1 and BRCA2 mutations differ from each other and from sporadic breast cancers. ${ }^{46}{ }^{47}$ Both are higher grade compared with sporadic cases. An excess of medullary/atypical medullary carcinoma has 
been reported in patients with BRCA1 mutations. ${ }^{48}{ }^{46}$ BRCA1 associated tumours are more likely than sporadic cancers to be steroid hormone receptor (oestrogen receptor (ER) and progesterone receptor (PR)) negative, CerbB2 negative, and to have mutations in the p53 gene. ${ }^{49}{ }^{50}$ In contrast, BRCA2 tumours are not different from sporadic cancers in their ER, $\mathrm{PR}$, or $\mathrm{p} 53$ status. The data derived form these studies, combining morphology and clinical data, have implications for clinical practice.

Grade is an independent prognostic indicator and is inversely related to outcome. ${ }^{51}$ The higher grade of BRCA1 associated tumours should have a worse prognosis than nonBRCA1 mutation carriers. Paradoxically, there are data within the literature suggesting that familial cancer in general, and medullary carcinomas in particular, have a better prognosis than ordinary ductal carcinomas, no special type. ${ }^{48}{ }^{52-55} \mathrm{~A}$ recent study suggests that the disease free interval and survival is not different from patients with sporadic breast cancers. ${ }^{56}$ In contrast, Foulkes et al have shown that the worse prognosis predicted by the higher grade is indeed correct. ${ }^{57}$ Data on prognosis in patients with BRCA2 mutations are scanty but preliminary reports suggest a similar prognosis to sporadic cancers. ${ }^{58} 59$

The use of breast cancer screening mammography in familial cancer is a controversial issue. It is likely to be replaced by ultrasound or magnetic resonance imaging. Whichever method is used, the pathology data (high grade, with a very high mitotic count and high proliferative index) suggests that the screening interval will have to be smaller than the present three years if interval cancers are to be avoided. The role of BRCA1 as part of a DNA repair complex also raises questions about radiation exposure, although at present there is no convincing evidence that the amount of radiation received by the patient during the mammographic screening is important

Finally, morphology might have a role in genetic counselling of patients. It has been estimated that patients who develop breast cancers between the age of 25 and 29 years, and who do not have an obvious history of breast cancer in the family, have a risk of approximately $6-7 \%$ for carrying mutations in the BRCA1 1 gene. ${ }^{60}$ On the assumption that the odds ratio from the analysis of the morphological features is independent of age, a patient under 30 years who has a high grade tumour (grade II or III) and who is also ER negative (D Easton 2000, personal communication) would have a risk of approximately $40-45 \%$ of harbouring a mutation in BRCA1. In the absence of these features the risk would be $3-4 \%$. Hence, the use of morphological and molecular features in addition to the clinical data may enhance the counselling of patients who are likely to harbour mutations in this gene.

1 Lakhani SR. The transition from hyperplasia to invasive carcinoma of the breast. F Pathol 1999;187:272-8.

2 Evans AJ, Pinder S, Ellis IO, et al. Screening-detected and symptomatic ductal carcinoma in situ: mammographic feasymptomatic ductal carcinoma in situ: mammographic fea-
tures with pathologic correlation. Radiology 1994;191:23740 .
3 Molloy M, Azarow K, Garcia VF, et al. Enhanced detection of preinvasive breast cancer: combined role of mammography and needle localization biopsy. F Surg Oncol 1989;40: $152-4$

4 Foote FW, Stewart FW. Lobular carcinoma in situ. $A m \mathcal{F}$ Pathol 1941:491-5.

5 Broder A. Carcinoma in situ contrasted with benign penetrating epithelium. $\mathcal{F A M A}$ 1932;99:1670-4.

6 Sonnenfeld M, Frenna T, Weidner N, et al. Lobular carcinoma in situ: mammographic-pathologic correlation of results of needle-directed biopsy. Radiology 1991;181: 363-7.

7 Urban J. Bilaterality of cancer of the breast: biopsy of the opposite breast. Cancer 1967;20:1867-70.

8 Rosen PP, Senie R, Schottenfeld D, et al. Noninvasive breast carcinoma: frequency of unsuspected invasion and implicacarcinoma: frequency of unsuspected invasion an
tions for treatment. Ann Surg 1979;189:377-82.

9 Rosen PP, Braun DW, Jr, Lyngholm B, et al. Lobular carcinoma in situ of the breast: preliminary results of treatment by ipsilateral mastectomy and contralateral breast biopsy. Cancer 1981;47:813-19.

10 Page DL, Kidd TE, Jr, Dupont WD, et al. Lobular neoplasia of the breast: higher risk for subsequent invasive cancer predicted by more extensive disease. Hum Pathol 1991;22: 1232-9.

11 Rosen PP, Kosloff C, Lieberman PH, et al. Lobular carcinoma in situ of the breast. Detailed analysis of 99 patients with average follow-up of 24 years. Am 7 Surg Pathol 1978;2:225-51.

12 Nielsen M, Jensen J, Andersen J. Precancerous and cancerous breast lesions during lifetime and at autopsy. A study of 83 women. Cancer 1984;54:612-15.

13 Wheeler JE, Enterline HT, Roseman JM, et al. Lobular carcinoma in situ of the breast. Long-term follow-up. Cancer 1974;34:554-63.

14 Wheeler JE, Enterline HT. Lobular carcinoma of the breast in situ and infiltrating. Pathol Anпи 1976;11:161-88.

15 Haagensen CD, Lane N, Lattes R, et al. Lobular neoplasia (so-called lobular carcinoma in situ) of the breast. Cancer 1978;42:737-69.

16 Moll R, Mitze M, Frixen UH, et al. Differential loss of E-cadherin expression in infiltrating ductal and lobular E-cadherin expression in infiltrating ductal and
breast carcinomas. Am 7 Pathol 1993;143:1731-42.

17 Rasbridge SA, Gillett CE, Sampson SA, et al. Epithelial (E-) and placental (P-) cadherin cell adhesion molecule expression in breast carcinoma. F Pathol 1993;169:245-50.

18 Lakhani S, Collins N, Sloane J, et al. Loss of heterozygosity in lobular carcinoma in situ of the breast. $\mathcal{F}$ Clin Pathol: $\mathrm{Mol}$ Pathol 1995;48:M74-8.

19 Nayar R, Zhuang Z, Merino MJ, et al. Loss of heterozygosity on chromosome $11 \mathrm{q} 13$ in lobular lesions of the breast using tissue microdissection and polymerase chain reaction. Hum Pathol 1997;28:277-82.

20 Berx G, Cleton-Jansen AM, Nollet F, et al. E-cadherin is a tumour/invasion suppressor gene mutated in human lobular breast cancers. EMBO $\mathcal{F}$ 1995;14:6107-15.

21 Berx G, Cleton-Jansen AM, Strumane K, et al. E-cadherin is inactivated in a majority of invasive human lobular breast cancers by truncation mutations throughout its extracellular domain. Oncogene 1996;13:1919-25.

22 Vos CB, Cleton-Jansen AM, Berx G, et al. E-cadherin inactivation in lobular carcinoma in situ of the breast: an early event in tumorigenesis. Br F Cancer 1997;76:1131-3.

23 Perou CM, Sorlie T, Eisen MB, et al. Molecular portraits of human breast tumours [in process citation]. Nature 2000;406:747-52.

24 Dupont WD, Page DL. Risk factors for breast cancer in women with proliferative breast disease. $N$ Engl $7 \mathrm{Med}$ 1985;312:146-51.

25 Tavassoli FA, Norris HJ. A comparison of the results of long-term follow-up for atypical intraductal hyperplasia long-term follow-up for atypical intraductal hyperplasia and intrad 29 .

26 McDivitt RW, Stevens JA, Lee NC, et al. Histologic types of benign breast disease and the risk for breast cancer. The cancer and steroid hormone study group. Cancer 1992;69: 1408-14.

27 London SJ, Connolly JL, Schnitt SJ, et al. A prospective study of benign breast disease and the risk of breast cancer [published erratum appears in $7 A M A$ 1992;267:1780]. fAMA 1992;267:941-4.

28 Page DL, Rogers LW. Combined histologic and cytologic criteria for the diagnosis of mammary atypical ductal hyperplasia. Hum Pathol 1992;23:1095-7.

29 Schnitt SJ, Connolly JL, Tavassoli FA, et al. Interobserver reproducibility in the diagnosis of ductal proliferative breast lesions using standardized criteria [see comments]. Am $₹$ Surg Pathol 1992;16:1133-43.

30 Sloane JP, Ellman R, Anderson TJ, et al. Consistency of histopathological reporting of breast lesions detected by screening: findings of the UK National External Quality Assessment (EQA) Scheme. Eur f Cancer 1994;30A:141419.

31 Sloane JP, Amendoeira I, Apostolikas N, et al. Consistency achieved by 23 European pathologists from 12 countries in diagnosing breast disease and reporting prognostic features of carcinomas. European Commission working group on breast screening pathology. Virchows Arch 1999;434:3-10.

32 Elston CW, Sloane JP, Amendoeira I, et al. Causes of inconsistency in diagnosing and classifying intraductal proliferasistency in diagnosing and classifying intraductal prol
tions of the breast. Eur $\mathcal{F}$ Cancer 2000;36:1769-72.

33 Lakhani SR, Collins N, Stratton MR, et al. Atypical ductal hyperplasia of the breast: clonal proliferation with loss of 
heterozygosity on chromosomes $16 \mathrm{q}$ and $17 \mathrm{p} .7$ Clin Pathol 1995;48:611-15.

34 O'Connell P, Pekkel V, Fuqua S, et al. Molecular genetic studies of early breast cancer evolution. Breast Cancer Res Treat $1994 \cdot 32 \cdot 5-12$.

35 Chuaqui RF, Zhuang Z, Emmert-Buck MR, et al. Analysis of loss of heterozygosity on chromosome $11 \mathrm{q} 13$ in atypical ductal hyperplasia and in situ carcinoma of the breast. $A m$ f Pathol 1997;150:297-303.

36 O'Connell P, Pekkel V, Fuqua SA, et al. Analysis of loss of heterozygosity in 399 premalignant breast lesions at 15 genetic loci. f Natl Cancer Inst 1998;90:697-703.

37 Berger MS, Locher GW, Saurer S, et al. Correlation of c-erbB-2 gene amplification and protein expression in human breast carcinoma with nodal status and nuclear grading. Cancer Res 1988;48:1238-43.

38 Slamon DJ, Clark GM, Wong SG, et al. Human breast cancer: correlation of relapse and survival with amplification of the HER-2/neu oncogene. Science 1987;235:17782 .

39 Varley JM, Swallow JE, Brammar WJ, et al. Alterations to either c-erbB-2(neu) or c-myc proto-oncogenes in breast carcinomas correlate with poor short-term prognosis.

40 Allred DC, Clark GM, Molina R, et al. Overexpression of HER-2/neu and its relationship with other prognostic factors change during the progression of in situ to invasive breast cancer. Hum Pathol 1992;23:974-9.

41 Gusterson BA, Machin LG, Gullick WJ, et al. Immunohistochemical distribution of c-erbB-2 in infiltrating and in situ breast cancer. Int $\mathcal{F}$ Cancer 1988;42:842-5.

42 Poller DN, Galea M, Pearson D, et al. Nuclear and flow cytometric characteristics associated with overexpression of the c-erbB-2 oncoprotein in breast carcinoma. Breast Cancer Res Treat 1991;20:3-10.

43 Ramachandra S, Machin L, Ashley S, et al. Immunohistochemical distribution of c-erbB-2 in in situ breast carcinoma-a detailed morphological analysis. I Pathol carcinoma-a

44 Gusterson BA, Machin LG, Gullick WJ, et al. c-erbB-2 expression in benign and malignant breast disease. $\mathrm{Br} \mathscr{f}$ expression in benign a

45 Pegram MD, Lipton A, Hayes DF, et al. Phase II study of receptor-enhanced chemosensitivity using recombinan humanized anti-p185HER2/neu monoclonal antibody plus cisplatin in patients with HER2/neu-overexpressing metastatic breast cancer refractory to chemotherapy treatment f Clin Oncol 1998;16:2659-71.

46 Lakhani S, Easton D, Stratton MR. Pathology of familia breast cancer: differences between breast cancers in carriers of BRCA1 or BRCA2 mutations and sporadic cases. Breast cancer linkage consortium. Lancet 1997;349: cases. Br $1505-10$

47 Lakhani SR, Jacquemier J, Sloane JP, et al. Multifactorial analysis of differences between sporadic breast cancers and cancers involving BRCA1 and BRCA2 mutations. 7 Natl Cancer Inst 1998;90:1138-45.

48 Marcus JN, Watson P, Page DL, et al. Hereditary breast cancer: pathobiology, prognosis, and BRCA1 and BRCA2 gene linkage [see comments]. Cancer 1996;77:697-709.

49 Crook T, Crossland S, Crompton MR, et al. p53 mutations in Brcal-associated familial breast cancer [letter]. Lancet 1997;350:638-9.

50 Osin P, Crook T, Powles T, et al. Hormone status of in-situ cancer in BRCA1 and BRCA2 mutation carriers [letter]. Lancet 1998;351:1487.

51 Elston CW, Ellis IO. Pathological prognostic factors in breast cancer. I. The value of histological grade in breast cancer: experience from a large study with long-term cancer: experience from a large study

52 Porter DE, Cohen BB, Wallace MR, et al. Breast cancer incidence, penetrance and survival in probable carriers of BRCA1 , pene mutation in families linked to BRCA 1 on chromosome 17q12-21. Br f Surg 1994;81:1512-15.

53 Eisinger F, Stoppa-Lyonnet D, Longy M, et al. Germ line mutation at BRCA1 affects the histoprognostic grade in hereditary breast cancer. Cancer Res 1996;56:471-4.

54 Eisinger F, Jacquemier J, Charpin C, et al. Mutations at BRCA1: the medullary breast carcinoma revisited. Cancer Res 1998;58:1588-92.

55 Eisinger F, Nogues C, Birnbaum D, et al. Low frequency of ymph-node metastasis in BRCA1-associated breast cancer [letter]. Lancet 1998;351:1633-4.

56 Verhoog LC, Brekelmans CT, Seynaeve C, et al. Survival and tumour characteristics of breast-cancer patients with germline mutations of BRCA1 [in process citation]. Lancet 1998;351:316-21.

57 Foulkes WD, Wong N, Rozen F, et al. Survival of patients with breast cancer and BRCA1 mutations [letter]. Lancet 1998:351:1359-60.

58 Gaffney DK, Brohet RM, Lewis CM, et al. Response to radiation therapy and prognosis in breast cancer patients with BRCA1 and

59 Robson M, Rajan P, Rosen PP, et al. BRCA-associated breast cancer: absence of a characteristic immunophenotype. Cancer Res 1998;58:1839-42.

60 Ford D, Easton DF, Peto J. Estimates of the gene frequency of BRCA1 and its contribution to breast and ovarian cancer incidence. Am f Hum Genet 1995;57:1457-62. 